\title{
Long-term follow-up after the arterial switch operation: Not as perfect as we would have hoped?
}

\author{
Mark G. Hazekamp, MD, PhD
}

See related article on pages 1089-94.

Lo Rito and colleagues ${ }^{1}$ studied the long-term fate of the aortic valve in a cohort of patients who received a followup 15 to 25 years after undergoing an arterial switch operation (ASO). Endpoints in the study were survival, aortic valve function, and reoperation on the aortic valve and/or aortic root. Survival is comparable to that in other published series. Aortic valve insufficiency (AoI) that was graded moderate or more than moderate, along with left ventricular dilatation and clinical symptoms, led to reoperation in 5 patients $(1.6 \%)$ : 1 valve repair, 1 homograft root replacement, 2 mechanical valve replacements, and 1 Bentall procedure. With the exception of 1 operation early after the ASO, the remaining 4 reoperations took place between 8.5 and 15.5 years after the initial ASO.

Freedom from moderate or more-than-moderate AoI at 10 and 20 years was $97 \%$ and $80 \%$, respectively, with a decline after 15 years. Presence of ventricular septal defect before pulmonary artery banding, and age at the time of the ASO, were not found to be risk factors. However, even mild AoI occurring immediately after the ASO was a significant risk factor for later development of moderate or more-thanmoderate AoI. The technique of coronary transfer (button or trapdoor technique) did not play a role in the development of aortic valve regurgitation, as the trapdoor technique was universally employed.

The incidence of aortic valve reoperation is low, but it may increase at later follow-up. Several patients in this series have significant AoI, but as yet, do not fulfill the criteria for aortic valve surgery. A $20 \%$ incidence of significant AoI at 20 years follow-up is worrying and warrants careful monitoring of these patients.

The authors do not provide aortic root diameters, which might have given us more insight into the process of how AoI develops late after an ASO. Risk factors for root dilatation and AoI that were found by others, ${ }^{2}$ such as

From the Department of Cardiothoracic Surgery, Leiden University Medical Center, Leiden, The Netherlands.

Disclosures: Author has nothing to disclose with regard to commercial support.

Received for publication Dec 11, 2014; accepted for publication Dec 11, 2014; available ahead of print Jan 23, 2015.

Address for reprints: Mark G. Hazekamp, MD, PhD, Department of Cardiothoracic Surgery, University Hospital Leiden, D6-S, PO Box 9600, 2300 RC Leiden, The Netherlands (E-mail: m.g.hazekamp@lumc.nl).

J Thorac Cardiovasc Surg 2015;149:968

$0022-5223 / \$ 36.00$

Copyright (C) 2015 by The American Association for Thoracic Surgery

http://dx.doi.org/10.1016/j.jtcvs.2014.12.026 presence of ventricular septal defect before pulmonary artery banding, could not be demonstrated in this study. Several studies suggest that aortic root dilatation has a relationship to AoI. ${ }^{3,4}$ Aortic root diameters have been reported to grow linearly and disproportionally after an ASO, and this growth does not stabilize in adulthood. ${ }^{5}$ When aortic root diameters exceed 5 to $6 \mathrm{~cm}$, root replacement must be considered, as the risk of rupture is higher. In particular, the anterior part of the aortic root that lies directly under the pulmonary artery bifurcation has been observed to be extremely thin-walled in some instances. ${ }^{6}$ Aortic valve regurgitation may present alone or in combination with a dilated aortic root. The indication for aortic valve surgery will be determined by the severity of regurgitation, symptoms, and dilatation or dysfunction of the left ventricle.

Surgery of the aortic root and valve can be safely redone, as Lo Rito and colleagues ${ }^{1}$ have demonstrated. Surgical access is more difficult after a Lecompte procedure, but exposure is greatly facilitated by complete transection of the pulmonary trunk just distal to the pulmonary valve. Some centers that started performing the ASO early after its introduction now have cases of follow-up of as much as 37 years. They report that root dilatation does not stabilize with time and may lead to an increasing number of indications for surgery. 5,6

The article from Lo Rito and colleagues ${ }^{1}$ is important, as it reminds us that the ASO, in the long run, is not as perfect as we might have hoped initially. Furthermore, it tells us that with longer follow-up periods, more patients may need reoperation for AoI, and probably aortic root dilatation as well. Careful monitoring of these patients is therefore essential.

\section{References}

1. Lo Rito M, Fittipaldi M, Haththotuwar R, Jones TJ, Khan N, Clift P, et al. Longterm fate of the aortic valve after arterial switch operation. J Thorac Cardiovasc Surg. 2015;149:1089-94.

2. McMahon CJ, Ravekes WJ, Smith EO, Denfield SW, Pignatelli RH, Altman CA, et al. Risk factors for neo-aortic root enlargement and aortic regurgitation following arterial switch operation. Pediatr Cardiol. 2004;25: 329-35.

3. Co-Vu JG, Ginde S, Bartz PJ, Frommelt PC, Tweddell JS, Earing MG. Long-term outcomes of the neoaorta after arterial switch operation for transposition of the great arteries. Ann Thorac Surg. 2013;95:1654-9.

4. Schwartz ML, Gauvreau K, del Nido P, Mayer JE, Colan SD. Long-term predictors of aortic root dilation and aortic regurgitation after arterial switch operation. Circulation. 2004;110(11 Suppl 1):II128-32.

5. van der Bom T, van der Palen RL, Bouma BJ, van Veldhuisen SL, Vliegen HW, Konings TC, et al. Persistent neo-aortic growth during adulthood in patients after an arterial switch operation. Heart. 2014;100:1360-5.

6. Koolbergen DR, Manshanden JS, Yazdanbakhsh AP, Bouma BJ, Blom NA, de Mol BA, et al. Reoperation for neoaortic root pathology after the arterial switch operation. Eur J Cardiothorac Surg. 2014;46:474-9. 